\title{
Work Conditions and Job Mobility in the Australian Indoor Sex Industry
}

\author{
by Fairleigh Evelyn Gilmour
}

Otago University

Sociological Research Online, 21 (4), 14

<http://www.socresonline.org.uk/21/4/14.html>

DOI: $10.5153 /$ sro.4166

Received: 12 Jun 2016 | Accepted: 8 Nov 2016 I Published: 30 Nov 2016

\begin{abstract}
This article explores sex workers' experiences of work conditions and job mobility in the indoor sectors of the Australian sex industry: brothel work, escort work and small cooperative work. Drawing from 14 in-depth life-narrative interviews with sex workers and former sex workers, it explores the key challenges faced by participants in navigating regulation and carving out a safe and lucrative working space. It offers a critical account of job flexibility and mobility in the sex industry and argues that the availability of increased options in a decriminalized setting means a greater range of potential spaces for workers to negotiate a suitable work environment.
\end{abstract}

Keywords: Sex Work, Working Conditions, Sex Work Legislation, Australia, Mobility, Decriminalisation

\section{Introduction}

1.1 This article explores sex workers' experiences of work conditions and job mobility in the indoor sectors of the Australian sex industry: brothel work, escort work and small cooperative work. In particular, through fourteen in-depth life narrative interviews with sex workers and former sex workers, it explores the key challenges faced by participants in navigating regulation and carving out a safe and lucrative working space, as well as positioning these career trajectories within the broader gendered labour market. As I will show, job mobility and flexibility emerge as key elements in participants' experiences of work conditions in the sex industry. Mobility and flexibility in this context can include the ability to enter and exit the industry, but also to move quickly and easily from one brothel to another, or from one sector of the industry to the other, such as from brothel work to escorting. Indeed, mobility can be identified as a central strategy that sex workers use in order to protect themselves from bad work conditions and find better ones.

1.2 Financial need and poor alternative work options were key reasons that participants gave for entering the industry. Specifically, experiences of unemployment and poor labour conditions in previous jobs prompted entries into the sex industry. Once in the industry, as a whole, my participants appeared to agentically navigate limiting regulations, and most were largely positive about their experiences in the sex industry. However, simultaneously, they described little recourse when faced with discriminatory or exploitative work environments. Several participants observed that that they were required to shop around for a new workplace when their basic rights had been threatened - such as refusing clients and requiring safe sex. Some workers were less able to make these movements, making it more difficult for them to access adequate work conditions. 
hospital) [1] and brothels and home businesses come under the purview of regulatory bodies for other businesses, in particular local council planning permits. It must be noted that there is significant variation between NSW local councils' willingness to treat sex work businesses as legitimate businesses. In Victoria sex work has been legalised, but the onerous licensing requirements mean that a two-tiered industry has developed with a large number of businesses and workers operating illegally. Research in Australia suggests that there are significant benefits to decriminalization, including improved health service provision (Harcourt et al. 2010), high compliance, increased transparency, and the social inclusion of sex workers (Scarlet Alliance 2010); and the positioning of sex work within existing general business and planning schema which offers greater opportunities for inclusion of sex workers as workers, resulting in opportunities for security and safety (Crofts et al. 2012, p. 395). The licensing system in Victoria, on the other hand, has been criticised by researchers and sex worker support and advocacy organisations, not least for creating a two-tiered system in which many workers are still criminalized (Crofts et al. 2012; McMahon \& Scarlet Alliance 2005; RhED 2009/2014). The narratives of my participants indicate that a decriminalized system may offer a greater range of possible work options, and thus greater autonomy for workers.

\section{Methodology}

2.1 Sex work varies enormously in its forms and social contexts (Bernstein 2007; Harcourt \& Donovan 2005) Studies have shown significant differences between sex workers working in different sectors in terms of violence and other occupational risks, particularly between indoor and outdoor sectors (Church et al. 2001; Seib 2007). Research on sex workers has tended to examine the experiences of street workers, despite the fact that in many countries, including Australia, this is the least prevalent form of sex work (Weitzer 2009: p. 217). This article therefore seeks to examine the experiences of women who have worked indoors. However, there is not a simple divide between indoor/outdoor workers and three participants worked on the street during their sex work careers, as well as working in indoor settings.

2.2 Moreover, I sought to examine the experiences of those who were at different points in their career trajectories. This was to allow for a more thorough examination of the experience of career movements and decisions over time. All recruitment was done by posting on Facebook (Ask a Sex Worker a Question) and adult services websites (Cracker, Locanto) as well as by advertising in the adult section of local newspapers in jurisdictions where it was legal to do so (The Canberra Times). I sought interviews with representatives of all the major organisations in the jurisdictions under study (although one organisation declined to participate) and their expertise and knowledge of the industry has been invaluable to the project.

2.3 In a context in which sex workers constitute a hard-to-reach sample (Benoit et al. 2005), and therefore large number of participants are not an option, I chose in depth interview as a method to illuminate some of the experiences of women working in specific local markets. Interviews were open-ended life narrative interviews, which, apart from asking demographic information, began with the statement 'So tell me about your work history, from when you started up until now'. I only sought clarification and more detail as they told their story. At the end of the interview I asked participants, 'What were the most positive and negative aspects of working in the industry?'.

2.4 The fourteen women I interviewed ranged in age from age 26 to 50 years at the time of the interview. Participants' age of entry into sex work ranged from 15 to 33 years with an average age of 23 years. Two participants entered the industry as minors. The time spent working in the industry ranged from six months to 25 years, with an average of 13 years. This represents the time from first entering the industry until final transition out (or time of interview for those still working). At the time of the interview, five women were still currently working in the sex industry, four were in the process of transitioning, and five were fully out of the industry. Many participants worked only part-time, or moved frequently into and out of the industry. Four participants worked in the ACT, eight in NSW, and six in Victoria. All participants had worked in a brothel, nine had worked independently or as escorts, three had worked on the street, four had worked in BDSM, four had worked as strippers, six had worked in brothel management or reception, one had worked in pornography and one had worked in erotic performance. Twelve participants were Caucasian, one was Maori and one Pasifika. All were Australian or New Zealand citizens [2]. Five participants had children while working in the industry, four of whom were single mothers, while another had care responsibilities for a sick family member. Ten participants undertook tertiary study while in the industry.

\section{The broader economic context}

3.1 As Maher and Pickering (2009: p. 1) have argued, the 'noisy discursive space' constructed around the 
Australian sex industry focuses on issues such as 'criminalization, harm, exploitation and stigma', thus obscuring key issues around work conditions and the broader gendered economy. Findings from this study reflect recent Australian research that has found that women enter the industry for primarily economic reasons (Groves et al. 2008; Maher, Pickering \& Gerard 2013; Pickering, Maher \& Gerard 2009). While some participants reported additional goals, money and/or work conditions were key motivating factors for all. Before entering the industry participants were not particularly well placed within the job market in terms of education or skills. The participants described various economic imperatives that reflect the challenges posed by the economic climate in which they made their labour choices.

Several participants were dealing with unemployment at the time of their entry into the industry. Tyra and Leslie had both recently lost their jobs: 'I'd lost my job at the same time so it was a bit difficult' (Tyra, former worker; brothel and escort; Vic) and 'It was basically three months of me trying to find work' (Leslie, transitioning out of industry; brothel; NSW and ACT). Meredith (former worker; brothel and receptionist; NSW) was struggling to find an entry point into the workforce. She had significant debt and describes her difficulty obtaining alternative employment:

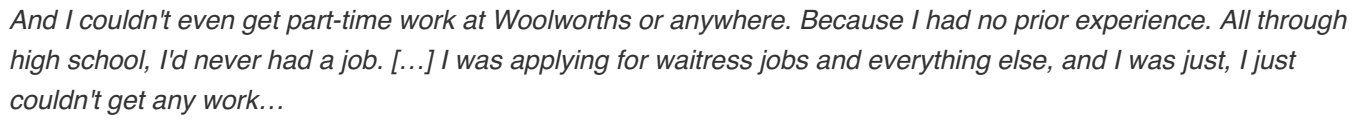

3.3 In situations of economic difficulty, sex work was seen as a good option and a way out of a bad situation. As Tyra (former worker; brothel and escort; Vic) said:

What other industry can you just walk straight into without any experience or any knowledge and make really good money? And have that flexibility? So it's great that there's an option there for women.

3.4 Prior to working in the industry, participants had largely been employed in nursing, retail and hospitality. Poor work conditions in these jobs were another key factor in the decision to move into sex work. Emmie (current worker; brothel and escort; ACT) stated that nursing was "just the crappiest job", while Nancy (current worker; brothel, escort and co-op, Vic and NSW) said of retail: "I think the metaphorical and literal fucking was getting a little bit too blurred so... It's probably easier to do it in a building where they give you lube".

Relationship breakdown and childcare responsibilities contributed to several participants' decision to enter the sex industry. Four participants entered the industry as single mothers. Other research studies into the Australian sex industry have also noted that a large proportion of sex workers are single mothers (Groves et al. 2008; Pickering, Maher \& Gerard 2009). The single mothers in this study reported previously being on welfare payments or low incomes and being unable to provide necessities such as healthcare, food and rent. Emmie (current worker; brothel and escort; ACT) describes her decision to enter the industry:

\footnotetext{
I had broken up with my husband three years earlier and I had four children [...] I couldn't let my children go on any school camps [...] They needed to get their teeth done, two of them did, and the bill was twelve thousand dollars and I just felt really very desperate because I couldn't find money very quickly for anything.
}

3.6 Tyra's (former worker; brothel and escort; Vic) entry into the sex industry was prompted by the pressure to provide for her child as a single mother:

I started working when I left my husband and I just sort of went through [...] I'd been with him for twelve years so it
was a bit hard. And I'd lost my job at the same time so it was a bit difficult. I just had no other income besides
parenting payments which I went onto. But it just wasn't enough to cover rent.

3.7 For single mothers, however, sex work was not just seen as a way out of poverty. The flexibility of sex work meant that they could mother the way they wanted to and spend considerable time with their children. As Natalia (former worker; brothel and escort; ACT, NSW and Vic) stated:

\footnotetext{
Because my custody with my child was week on/week off, it meant that the week that I didn't have her, I could work 24/7 for that week and then the following week be the stay-at-home mum that I always wanted to be. But you can't be that when you're doing a normal job because they tend to frown on you wanting to take a week off every second week. And I've not yet come across a part-time job that will allow you to do that either. And considering she was only like one or two, I wanted to be home during the day for her. So that gave me that flexibility.
}

3.8 This flexibility was also key for students, and 10 of the 14 participants undertook tertiary study while in the industry. Natalia observed that this form of work was ideal for a sex worker: 
I could waitress all night, be late to my classes in the morning and not get any study done. Or I could be a sex worker, and I could study, get my assignments written in between intros and bookings, make enough money and still get to uni on time the next morning.

3.9 Some participants faced additional difficulties in securing mainstream employment due to health issues, mental health problems or periods of emotional distress. A significant proportion of participants (5 of 14) described mental health problems. Previous studies indicate that this is not true for the indoor industry as a whole: research in the Australian and New Zealand context has not indicated higher rates of mental health issues among indoor sex workers than control groups (Romans et al. 2001; Seib, Fischer \& Najman 2009). Centrally, the five participants who have had mental health problems described these health problems as existing prior to their entry into the industry. Participants' narratives suggest that sex industry work was particularly appealing to those with mental health problems because of the flexibility of the work. These narratives have to be considered in terms of the broader economic climate in which participants were making labour choices. Participants struggled to find quality alternative employment, and this issue was exacerbated by health problems. Barriers to work are particularly evident for those with mental health problems in the Australian labour market, with mental health being both a consequence of, and risk factor for, unemployment (Oleson et al. 2013).

3.10 Sallie (transitioning out of industry; brothel; Vic and NSW) emphasised that sex work is a job that she could go to, even in times of emotional distress, because of the very flexible working hours in the industry. While Sallie's experience of sex work was largely negative, and working in the industry contributed to her anxiety, she identifies sex work as one of her only realistic options:

When I've had issues with my mental health, there's no other job that you can have that you can step away from when you need to, and maybe pick up a shift once a week to keep yourself going, whilst you're dealing with whatever it is, whatever angst is going on.

3.11 Like Sallie, Monica (current worker; brothel, escort, porn and management; Vic) sees sex work as one of her only realistic options, due to the flexible working hours:

I have a mental illness [...] I think it's probably true of a lot of people who have any sort of [...] disability's the wrong word [...] any sort of issues going on where they need to have flexibility and they need to have short working hours. It's really difficult to find other work that is comparable.

3.12 Broader economic conditions shaped participants' decisions to enter the industry, with a lack of alternative, adequately flexible employment being a key consideration for many. Broader economic conditions also have an impact on work conditions within the industry. Sallie (transitioning out of industry; brothel; Vic and NSW) and Natalia (former worker; brothel and escort; ACT, NSW and Vic) - who had worked in connection with the industry in some way for over 25 years and 14 years respectively) - both suggested that they were more often encountering women who were providing unprotected sexual services and stated that this shift is due to more women turning to sex work because of economic pressure. The increase in worker numbers increases competition in the market. As Sallie states:

It was a different world then than what it is now [...] There weren't high-risk behaviours of no condom. It was a lot healthier back then. Now you have brothels everywhere. There's so many brothels. There's so many illegal brothels. And you have such competition in the industry that you have so many more women. And so many more that are willing to do high-risk services - offer everything to get a book. And you have owners that pressure you into offering [high-risk services].

3.13 Sallie argues that the increase in high-risk services is directly related to the increasing number of workers who are entering the industry because of a lack of other viable options:

You've got an economic situation where it's harder and harder for people to keep above. So you've got more and more young women that are students, a lot more single mums, more and more women who are needing to supplement their income. And you've got higher competition, not only in the number of parlours but in the number of women working. And there's more and more pressure to offer more and more.

3.14 Similarly, Natalia (former worker; brothel and escort; ACT, NSW and Vic) reports that in the ACT, the standards have changed since her time working in the industry, and she also thinks that this shift towards more unprotected sex is due to economic pressure: 'Again, because of the downturn in the economy, there's more workers, less bookings. So there's more chance that they're doing oral or sex with no condom.' In Kontula's (2008) research on the Finnish sex trade, she observed that work conditions are improved when there are fewer workers: When demand exceeds supply, the sex worker can pick and choose her customers and 'this seems to be one of the most important factors in the autonomy' (Kontula 2008: 616) of a sex worker. 
3.15 The availability of other jobs and social benefits would thus appear to have a significant impact on the internal power relations of commercial sex transactions - to the benefit of workers in Finland, and to the detriment of workers in Australia who face increasingly limited options in terms of both alternative job options and adequate welfare provisions. Australia has recently introduced policy reforms to the Disability Support Pension criteria (Bowden 2015), forcing people onto the extremely low Newstart payments and making it even harder for those with disabilities to access welfare. In July 2006, welfare-to-work policies were introduced for single parents in Australia and represented a sharp increase in the obligations applying to single parents on income support (Grahame \& Marston 2012). Those with children aged over eight years were moved from the Parenting Payment to the much lower Newstart Allowance. This has resulted in increased poverty for single parents - usually mothers - and their children. Women's choices to enter the industry must be understood in terms of a broader gendered economy in Australia marked by structural violence including placing single mothers on the unliveably low Newstart payment and limiting access to Disability Support Payments, while failing to adequately address issues family-friendly work options, childcare, or mental health employment support.

3.16 Within this context of limited options, sex work can be a strategic option. Even within this context, sex work was not experienced by most participants as simply a last resort, even when initial entry was deeply constrained. Many participants approached their careers in a short-term goal-oriented or carefully strategic longterm way[3]. Nonetheless, in a context where there are fewer job options for those who need flexible work, an increasing supply of workers can impact on work conditions. Assessing the obstacles to safe and autonomous work conditions in the Australian industry is therefore of key importance. In the following sections, I examine how participants navigated their work in the industry.

\section{Navigating brothel work and independent work}

4.1 Decisions around whether to work independently or in a brothel were discussed by several participants, with independent work providing workers with greater autonomy than brothel work. As Emmie (current worker; brothel and escort; ACT) stated:

\footnotetext{
I didn't like that I had to follow someone else's rules [at the brothel] because when I'm selling myself on the phone, or selling my service, I am making the rules. I want to kiss because I like doing it. I charge appropriately. I want to do certain things so I charge appropriately. It's my rules.
}

Independent work is also better remunerated. As Tyra (former worker; brothel and escort; Vic) noted: 'There's a big difference. So there's a lot more money [in escorting] and there was a lot more work'. While higher wages are ideal in themselves, the higher rate per job also means that private workers need to work less, are better able to choose hours that suit them, and are also more able to be choosy in terms of selecting clients. As Lorena (transitioning out; brothel, escort and street; NSW) observed:

I've always said, if they're not easy enough to become my regulars, then I don't want to see them again. So they've got to be really easy clients for me to see them again.

4.3 Despite the benefits of working independently several participants expressed concerns around its safety. Lorena, who had worked in a brothel, as an escort and on the street put it bluntly:

\footnotetext{
Escorting would be riskier than brothel work. Cos you're in a house and you've got security and there's people in that house. If someone's gonna do something to you, they're not gonna have witnesses all around, yeah? Yeah, massage and brothel work is definitely safer than street and escort.
}

4.4 The trade-off in this situation is thus between autonomy and high earnings versus safety and legality (although there is significant variation between brothels in terms of safety, as I will discuss further). The ideal option for several participants was to work independently in co-ops or in pairs, although only one participant Nancy (current worker; brothel, escort and co-op; Vic and NSW), while working in NSW within City of Sydney council laws - was able to do this legally, working from an apartment with two other workers.

The work options available are constrained by the regulatory framework and system of licensing in each jurisdiction. In the ACT and in Victoria, cottage-style industries remain illegal despite numerous calls for their decriminalisation. There is potential for such businesses within the NSW regulatory schema. In Sydney, Nancy worked legally with two other workers from her home, in what would have been classified as Home Occupation Sex Service Premises. Working in the City of Sydney, which classifies Home Occupation Sex Service Premises as a home business, Nancy and her colleagues were able to work from a residential area, which Nancy argues added to the safety and pleasant work environment: 
I really liked it. Like it was much more relaxed. You could vet clients before they even came in. Like you'd email them back and forth a few times to make sure that, you know, they wanted what you offered. And that they were aware of what your limits were. And we never had any problems in the year that I worked there.

However while such a model offers both safety and autonomy to workers, not all NSW councils approach the planning and regulating of sex work businesses in the same way. Other councils are far more restrictive, classifying all sex work businesses as brothels and limiting where they can be located (such as not in residential areas, effectively banning home businesses) and it is thus unsurprising that while Nancy describes registering as 'the City of Sydney just - done, signs off on it', other workers in NSW, such as Lia (current worker; brothel; NSW), stated that they were unable to work from home in pairs because of council regulations. Decriminalisation alone is not adequate to address barriers to a greater range of work options because local council regulation in NSW has been shown to be highly ambivalent about sex work as legitimate employment (Crofts et al. 2012) while also failing to be consistent or fair in decisions regarding sex industry businesses (Scarlet Alliance 2012a). The situation in NSW is nonetheless still preferable to that in Victoria and the ACT, where cottage-style industries remain illegal despite numerous recommendations to legalise them (ISCHS 2009; Neave 1992). As one support and advocacy worker observed:

\begin{abstract}
I think the model in Victoria places so many unnecessary requirements on a person's work that it really does limit a person's autonomy, and right to have strong control over their occupational health and safety in their work place. And it limits and constricts where you can do sex work in a way that's absolutely illogical and also in opposition to cultural practices of the sex industry.
\end{abstract}

4.7 Several participants reported with others from home in jurisdictions where this is illegal because of the numerous benefits such a situation provides Natalia, (former worker; brothel and escort; ACT, NSW and Vic) worked illegally with another worker from home and reported that:

\begin{abstract}
I was working in a residential house with my girlfriend - so illegal - and neither of us were registered (...) I never felt threatened by any of the clients. (...) So for the worker, the biggest benefit is the OH\&S side of things (...) So less wear and tear, she would then be able to then not just be living in her work flat going "I really need to make rent this month."(...) Sometimes it is about safety. Just, if the client you're seeing just knows that there's somebody else in the place, he doesn't have to lay eyes on her, just that kind of thing, is the bonus.
\end{abstract}

4.8 However, working illegally obviously poses its own risks, including the risk of a criminal record and a lack of police protection. Joslyn (current worker; brothel, street and escort; Vic) stated: 'I think our biggest danger is police. Really I do,' while Lorena (transitioning out; brothel, escort and street; NSW) stated: 'I've been arrested. Which was horrible.'

4.9 For those who choose the benefits of brothel-work - such as security and not having to advertise or expend capital on equipment - the work conditions varied considerably. One key area in which there was a reported variation was in terms of the flexibility of shifts and work hours. This is particularly relevant because most workers were either parenting (four of 14) or studying (10 of 14) at some point during their sex work careers, or had other life circumstances that made it hard to hold down full time work, including mental health problems (five of 14) and drug addiction (two of 14). Flexible work hours were thus a key benefit of working in the sex industry.

4.10 How participants felt about working in brothels depended upon management approaches, which varied widely. Sallie and Nancy, for example, described starkly different experiences of management. Sallie (transitioning out of industry; brothel; Vic and NSW), working in Sydney, describes a situation where workers had little ability to assert their rights within the client-worker encounter:

So the guys often come in, especially nights, over the weekend, and they're on ice, they're on coke, they're on eccie. And particularly the ice guys will basically hammer you for as long as they've got you. And there's nothing you can do. If they're not happy with how it's gone, they can complain to the desk and the desk will give them their money back. And if you dare argue against that, then you're kicked out the door.

4.11 Nancy (current worker; brothel, escort and co-op; Vic and NSW), on the other hand, working in Victoria, describes how she approached disagreements between clients and workers when working in a management position:

If clients were rude, I just said, 'Kick them out. I don't care. I don't give a shit why you kick them out. If you don't want to deal with them, kick them out. Like if they're jerks? Out. Condom off? Out.' That's what I did. It's always worked for me, being very hardline in terms of safety. And so, if they ever kicked them out, I never asked why. 'Unless you want to tell me, if he's just being a prick, if he's got an STI, if he's rude, if he tries to stick it in the butt, just kick them out'. 
And then when they came downstairs and complained, I'm like 'Did you see her naked? Yep? Then there's no refund'. Cos like [...] Be nice. I have never kicked someone out who is nice in a booking.

4.12 Among brothel workers there was also considerable variability in terms of ability to choose clientele. I asked Leslie (transitioning out of industry; brothel; NSW and ACT) if she could choose not to 'intro'[4] clients if she didn't want to see them. She replied:

\begin{abstract}
At Sunshine Parlour you couldn't, because it was a line-up situation [5]. And so you didn't have a choice. And they didn't have cameras in the girls' room so you could see who it was. And I think that's because they didn't want people to say no to almost everybody (laughs). At Moonlight Parlour, we did [have cameras] [...] So yeah, you could choose. At Moonlight Parlour, you could choose by just not going in to the intros. You didn't have to tell them, you just didn't go in.
\end{abstract}

4.13 There was significant variation described as to whether workers were obliged to see particular clients. As one support and advocacy worker stated, in critiquing the management test that managers in Victoria are required to undertake:

But to me, I think if you're going to have a manager's test, the things that come up for me are: Are you allowed to insist that a woman stays when she wants to go home? Are you allowed to insist that a woman has to introduce herself to every client? There's so many managers out there that are really pushy.

4.14 That managers and owners often do not acknowledge their obligations to workers has been identified as a significant barrier to worker rights (Scarlet Alliance 2012b). Sex workers working in brothels are usually classified as sub-contractors or contractors rather than employees, despite the fact that the requirements placed upon workers indicate that they are in fact employees (set shift times; strict regulations of behaviour, appearance and services with clients; hourly pay; many brothels prevent workers from working for other brothels or independently). The classification of sex workers as contractors is largely so that owners of sex industry businesses can avoid their industrial responsibilities, such as superannuation, sick pay and workers' compensation (Jones 2014). This ambiguity around rights and obligations is further exacerbated by the fact that sex workers find it particularly difficult to fight for their rights because it often means that they have to 'out' themselves, and this is something that owners and managers are aware of. Lia (current worker; brothel; NSW) describes her decision not to fight an unfair dismissal that resulted from her refusal to perform a highly risky act (a brown shower[6]):

Ah, well if the same thing had happened, not in the sex industry, I would have been the first person to take that to the appropriate authorities. But I didn't. Because obviously I would have had to come out as a sex worker. I felt the risk was greater than the gain.

4.15 Furthermore, brothels at which more marginalised workers work may be more likely to ignore OHS standards and create riskier work environments. Several participants noted that some owners/managers pressure workers into providing unsafe services. Workers who are less desirable by industry standards, or who have less relative bargaining power for various reasons (drug dependency, migration status, age), may be less able to insist on safe sex. Sallie (transitioning out of industry; brothel; Vic and NSW) notes that some brothels require workers to offer unprotected services:

There was one place I went to and there's a standard thirty minute booking fee and for ten dollars extra with no condom, oral. And you're told that in the interview. And clients are told that when they're making bookings.

4.16 Natalia (former worker; brothel and escort; ACT, NSW and Vic) also expressed concern at the existence of brothels where workers were pressured to perform unprotected services by owners and/or management:

[We were in] one of our Asian brothels. My girlfriend and I sat down, doing outreach, and there on the table is the price list for half an hour, 45 minutes, an hour. And no condom oral, this much extra. And I'm like - there it is, right out there in front of me, in the brothel.

4.17 When discussing the open advertising of oral without a condom, Natalia was describing a brothel where she noted many of the workers were likely to be migrant women working without working visas. In response to the signs advertising oral with no condom, she describes saying to the owner: "'If the cops come in here, you're so closed down buddy! Immigration will be in here" [...] He understood "Immigration". Next thing I know, no signs'. Sallie stated that the brothel she was referring to was known for employing drug-using workers: 'It's an infamous one in that most of the girls that work there are drug users'. Lia (current worker; brothel; NSW), meanwhile, describes her reasons for not wanting to work in mature-age brothels: 
It's just really pretty disgusting the way that old workers are treated. I've been to a couple of mature age brothels, but I refuse to work there. I didn't understand that 'mature age' meant blowjobs without condoms [...] I went to a couple but what they demand that you do is not within my boundaries so I just don't do it. It's quite disgusting.

4.18 Thus not only do managers and owners pressure workers into providing unsafe services, but some groups of workers, such as migrant workers without visas, older workers and drug using workers, are more likely to be exposed to such pressure. In spite of these struggles, it is important to note that most participants were largely positive about their time in the industry, and many described finding good employers. While this article focuses on the obstacles to good work conditions, many participants made comments such as Leslie's (transitioning out of industry; brothel; NSW and ACT):

They were great. Even the male managers at Starlight Parlour were excellent as well. They were really professional (...) They didn't flirt with the girls. They had a sense of humour and they were very professional.

4.19 The key issue is not therefore that sex work environments necessarily have poor work conditions.

Indeed, several participants described significantly better work conditions in the sex industry that in their previous jobs. Rather, participants were forced to negotiate their work conditions through mobility and flexibility:

participants largely described finding good work conditions by moving from one place of employment to another. While this has to be acknowledged as one central strategy for workers to resist against poor work conditions, this pattern of mobility invites critical examination, especially in the absence of a consistent approach to work safety and worker rights in the industry.

\section{Job mobility and flexibility}

5.1 Work in the sex industry is often characterised by mobility and sought for its flexibility. Several scholars have highlighted mobility as a central feature of sex work (Law 2011; Maher, Pickering \& Gerard 2013; Sanders 2005). Participants in Maher et al.'s (2013) study of brothel workers described considerable mobility into and out of the sex industry. There are several forms of employment flexibility provided in the sex industry, including control of working hours and ease of entry and exit. These forms of flexibility allowed workers to support specific financial goals and many workers experienced sex work as 'a permanent avenue for financial management or to attain a desired level of financial security' (Maher, Pickering \& Gerard 2013, p. 42). The flexibility of sex work has been noted to be particularly valuable to both mothers (Maher, Pickering \& Gerard 2013) and students (Lantz 2003; Maher, Pickering \& Gerard 2013), for whom the nexus of flexibility and pay is crucial, while the current study also shows the value of flexible work for those with temporary or ongoing mental health issues.

5.2 Participants in the current study emphasised the importance of flexibility and reported a high degree of job mobility. Most participants had moved in and out of the industry and into 'straight' work several times, most had moved between sectors of the industry, and most had moved between parlours. Many of these movements were in response to life circumstances and priorities. However, other movements represented a search for safe and adequate work conditions. Several participants moved into different industry sectors, or from one business to another in order to access safer working environments, and varying job mobility is a key issue here. Several participants changed place of employment in order to work in brothels where sexual health was a priority. Natalia (former worker; brothel and escort; ACT, NSW and Vic) described one instance in which she left one parlour for another:

\footnotetext{
[The manager] was just such a pig. And so I pulled out the Prostitution Act and the OH\&S and I highlighted all the sections that he wasn't meeting. And then I was like: 'You're going to need to look at those. You're supposed to be supplying the condoms. I shouldn't have to go and buy my own.' [...] And as I walked out of the office, the Prostitution Act and OH\&S went sailing past my head. And I was told to get out [...] So after two days I packed up my stuff and I left. Moved to another parlour.
}

5.3 Tyra (former worker; brothel and escort; Vic) left a place where management encouraged unsafe practices: 'It was sort of a little bit dodgy and that's when I decided to move on to somewhere else. So I wasn't happy with the quality of the place I was at.'

5.4 While some workers described considerable ease in moving from one brothel to another, this was less simple for other workers. Lia (current worker; brothel; NSW), for example, felt pushed out of the industry because of pressure as a mature age worker to perform unsafe services:

So if I envisage my career in the sex industry finishing, it's just that I would have gone through all the people that there are to work for. And either they won't have me back or I can't tolerate them. So there's a limited number of places where you can work [...] Because there isn't really a structure that would support me working and that the 
available options - which are work in a mature age place and do natural blowjobs and kiss old guys' feet [...] Yeah, so

there aren't really any options that I can see. My career will finish because there just aren't places that I can work.

5.5 The ability to move between different places of employment was also becoming less easy over time. Participants attributed this development to the increasing number of workers in the industry due to economic pressure in the Australian context, as has been outlined above. As Natalia (former worker; brothel and escort; ACT, NSW and Vic) states:

One of the beautiful things about working in the ACT ten years ago was that if you had an issue with management, you packed up your stuff and walked next door, to the brothel next door and started working there. They were more than happy to take you. But now, in this climate that we have now, [...] you don't have quite that freedom of movement any more. Which I think I would find really hard.

5.6 Lia (current worker; brothel; NSW), for example, is currently not able to move into straight employment because of health issues and wants to continue working in the sex industry. However, she also faces barriers to establishing a sex work career. While Lia argues that workers have few rights in the sex industry, she identities this situation as part of a broader pattern, 'I think that level of insecurity - and in neoliberalism you do have a really high level of insecurity - but in the sex industry, it's way worse'. Lia does not want to leave the industry, she simply feels unable to work within the current market. She does not want to work at mature age brothels because she has experienced pressure to perform unsafe services. Yet at the same time, Lia describes limited options in terms of safe private work - 'there's just no structure to support being a private worker'.

\section{Conclusion}

6.1 Participants described varying levels of work conditions, and raised key issues related to autonomy and safety. These elements appear to depend upon their desirability as a worker, the type of work they were doing, whether independent or brothel, the specific brothel at which they were working, and the jurisdiction in which they were working.

6.2 Furthermore, participants' work conditions and career decisions need to be understood within a broader gendered labour market in which work conditions are worsening and wage inequality is deepening. Considering the make-up of this particular study, the erosion of welfare provision for single mothers and those with mental health problems, in tandem with the increasing costs of education, need to be understood as the context within which sex work is chosen instead of other available forms of employment. Sex work was not, however, necessarily seen as a last resort, but was for some participants, part of a strategic career plan, or facilitated other life goals.

6.3 Participants agentically navigated limiting regulation in order to carve out a safe and lucrative working space. Nonetheless, participants described little legal recourse when faced with discriminatory or exploitative work environments, and often moved between brothels in order to find a good employer. While most participants were very positive about brothels they had worked in, the fact that they had to shop around for a brothel where their basic rights - such as refusing clients and requiring safe sex - were acknowledged, and that some workers were much less able to make these movements, is a cause for concern. Participants' ability to navigate shifts between industries and jobs may reflect a high level of individual aptitude, planning and resourcefulness, but this should not obscure the fact that this mobility is only a choice insofar as becoming a flexible and mobile worker is a response to insecure and inadequate employment in the broader labour market and within the sex industry. While dangers of exploitation are apparent in the industry, this is better conceptualised as the end result of neoliberal economic policies characterised by welfare cuts and the erosion of worker rights, rather than as intrinsic to sex work, as it is sometimes suggested. The historical lack of unionization because of past illegality and continued stigma of sex work (cf Gall 2006) contributes to worsen the lack of labour rights for workers, a lack which is however not particular to the sex industry. Participants often found work conditions in their prior jobs worse than those in the sex industry. Sex work in that sense appears to constitute a strategy of resistance to the position afforded by many poor women in the current economic climate.

6.4 My participants' work was clearly constrained by the legal framework and legal status of different forms of work in the jurisdictions under study. While participants negotiated and resisted the edges of legality, by working in pairs and refusing to register, for example, they were unable to change broader market structures, industry practices or client expectations. Furthermore, only one participant described working legally in a co-op and one illegally in a pair. Several participants discussed this sort of arrangement as being ideal but they were too scared to work illegally. Most participants felt limited to brothel work, which can pose problems of safety and autonomy for less 'desirable' workers, and working alone, which can pose OH\&S issues as well as lacking the 
camaraderie and support of working with others.

In terms of policy implications, my participants' narratives indicate that both in contexts where sex work is legal and in those where it is decriminalised sex workers still experience very serious forms of exclusion from labour rights. In particular, there are key issues that need to be addressed, such as the inability to work legally in cottage-style industries in the ACT and Victoria and the failure of some councils to allow home-based services in NSW. However the research suggests that decriminalisation is a better move in the direction of promoting better work conditions in the sex industry. Indeed, the availability of increased options in a decriminalized setting means a greater range of potential spaces for workers to carve out a suitable work environment. Decriminalization increases the potential for independent work, which not only frees workers from problematic brothel environments, but enables them to benefit from the flexibility that the industry provides in a way that doesn't compromise safety, by working in co-operative setups. This is particularly important in a context where labour rights are limited. As Lia put it:

The way I see it is - private workers should be given more rights, should be able to work more than one person so that you're not dependent upon these crazy brothel managers (...) The very best of them are a little fucked up.

\section{Notes}

Prostitution (Amendment) Bill 1983 (NSW).

All participants were therefore able to work legally in Australia (New Zealand citizens do not need a visa to work in Australia). This is a key limitation of the sample and was not deliberate, and reflects that migrant workers are a particularly hard-to-reach population. For a thoughtful discussion of migrant workers' experiences in the Victorian context see (Ham 2015).

The strategic and temporal nature of sex work career planning is discussed further in (Ham \& Gilmour 2016)

Introducing yourself to, and chatting with a potential client.

There is variation among brothels in how workers introduce themselves to clients. Some have a 'lounge' type situation where clients and workers mingle and chat. Some have one-on-one introductions, where each worker will introduce herself to the client one at a time. Some have a 'line-up' situation, which Leslie is describing, where all available workers stand in a line and introduce themselves to the client, who can then select which worker he would like to book time with.

As the name suggests, a brown shower is a sexual act that involves defecating on another person.

\section{References}

BERNSTEIN, E (2007), Temporarily Yours: Intimacy, Authenticity and the Commerce of Sex, The University of Chicago Press, Chicago and London.

BOWDEN, T (2015), 'Disability support pension eligibility crackdown forces people onto Newstart allowance: Welfare groups', ABC, Accessed 7/11/16, http://www.abc.net.au/news/2015-06-26/people-forced-offdisability-support-pension/6576516.

CHURCH, S, Henderson, M, Barnard, M \& Hart, G (2001), 'Violence by clients towards female prostitutes in different work settings: questionnaire survey', British Medical Journal, Vol. 332, no. 7285, p. 524-5.

CROFTS, P, Maher, J, Pickering, S \& Prior, J (2012), 'Ambivalent regulation: The sexual services industries in NSW and Victoria - Sex work as work, or as special category?', Current Issues in Criminal Justice, Vol. 23, no. 3, p. 393-412. 
GALL, G (2006), Sex Worker Union Organising: An International Study, Palgrave MacMillan, Basingstoke.

GRAHAME, T \& Marston, G (2012), 'Welfare-to-work policies and the experience of employed single mothers on income support in Australia: Where are the benefits?', Australian Social Work, Vol. 65, no. 1, p. 73-86.

GROVES, J, Newton, DC, Chen, MY, Hocking, J, Bradshaw, CS \& Fairley, CK (2008), 'Sex workers working with a legalised industry: their side of the story', Sexually Transmitted Infections, Vol. 84, no. 5, p. 393-4.

HAM, J (2015), 'Sex Work, Immigration and Social Difference', PhD Thesis, Monash University.

HAM, J \& Gilmour, F (2016), "We all have one': Exit plans as a professional strategy in sex work',Work, Employment \& Society, online first doi:10.1177/0950017016666198

HARCOURT, C \& Donovan, B (2005), 'The many faces of sex work',Sexually Transmitted Infections, Vol. 81, no. 3, p. 201-6.

HARCOURT, C, O'Connor, J, Egger, S, Fairley, CK, Wand, H, Chen, MY, Marshall, L, Kaldor, JM \& Donovan, B (2010), 'The decriminalisation of prostitution is associated with better coverage of health promotion porgrams for sex workers', Australian and New Zealand Journal of Public Health Vol. 34, no. 5, p. 482-6.

JONES, K (2014), 'Brothels continue to misunderstand the employee/contractor difference', Accessed 7/11/2016 http://safetyatworkblog.com/2014/02/10/brothels-continue-to-misunderstand-the-employeecontractordifference/.

KONTULA, A (2008), 'The sex worker and her pleasure', Current Sociology, Vol. 56, no. 4, p. 605-20.

LANTZ, S (2003), 'Sex work and study', Traffic, Vol. 3, p. 31-50.

LAW, T (2011), 'Not a Sob Story: Transitioning out of Sex Work', Masters Thesis, University of Ottawa.

MAHER, J \& Pickering, S (2009), 'Sex Work, Regulation and Social Noise', paper presented toThe Australian Sociological Assocation 2009 Annual Conference, Canberra, 1-4 December.

MAHER, J, Pickering, S \& Gerard, A (2013), Sex Work: Labour, Mobility and Sexual Services, Routledge, London and New York.

MCMAHON, M \& Scarlet Alliance (2005), Submission to the Victorian Government's review of the Prostitution Control Regulations, Accessed 7/11/16, http://www.scarletalliance.org.au/library/vic_sub0805.

NEAVE, M (1992), 'From difference to sameness - Law and women's work',Melbourne University Law Review, Vol. 18, no. 4, pp. 768-807.

OLESON, SC, Butterworth, P, Leach, LS, Kelaher, M \& Pirkis, J (2013), 'Mental health affects future employment as job loss affects mental health: Findings from a longitudinal study', BMC Psychiatry, Vol. 13, p. 144152.

PICKERING, S, Maher, J \& Gerard, A (2009), Working in Victorian Brothels, Consumer Affairs Victoria, Melbourne.

RHED (2009/2014), ISCH Psition Paper - Sex Work Legislation in Victoria, Inner South Community Health, Accessed 7/11/16, http://sexworker.org.au/wp-content/uploads/2015/09/RhED-Position-Paper-2014.pdf .

ROMANS, SE, Potter, K, Martin, J \& Herbison, P (2001), 'The mental and physical health of female sex workers: A comparative study', Australasian Psychiatry, Vol. 35, no. 1, p. 75-80.

SANDERS, T (2005), Sex Work: A Risky Business, Willan Publishing, Devon and Oregon.

SCARLET ALLIANCE (2010), Submission on Sex Industry Regulation in NSW,Accessed 7/11/16, http://www.scarletalliance.org.au/library/nswsub_0910/.

SCARLET ALLIANCE (2012a), Regulation Review - Local Government: Compliance and Enforcement, Independent Pricing and Regulatory Tribunal, Accessed 7/11/16,

http://www.scarletalliance.org.au/library/IPART06_2012/.

SCARLET ALLIANCE (2012b), 'Submission to the Review of the Fair Work Act 2009', Accessed 7/11/16, 
https://submissions.employment.gov.au/empforms/Archive/Fair-Work-Act-Review2012/Documents/ScarletAlliance.pdf.

SEIB, C (2007), 'Health, Well-being and Sexual Violence among Female Sex Workers: A Comparitive Study', PhD Thesis, Queensland University of Technology.

SEIB, C, Fischer, J \& Najman, JM (2009), 'The health of female sex workers from three industry sectors in Queensland, Australia', Social Science \& Medicine, Vol. 68, no. 3, p. 473-8.

WEITZER, R (2009), 'Sociology of sex work', Annual Review of Sociology, Vol. 35, p. 213-34. 